\title{
Expressions of microRNA-29a and microRNA-34a in pleomorphic adenomas of salivary glands
}

\author{
Igor Sergeevich Brodetskyi ${ }^{1}$, Vladislav O. Malanchuk ${ }^{1}$, Victor E. Dosenko ${ }^{2}$ \\ ${ }^{1}$ Department of Oral and Maxillofacial Surgery, Bogomolets National Medical University, Kyiv, Ukraine; ${ }^{2}$ Department of General and Molecular \\ Pathophysiology, Bogomoletz Institute of Physiology, NAS of Ukraine, Kyiv, Ukraine \\ Contributions: (I) Conception and design: All authors; (II) Administrative support: VO Malanchuk, VE Dosenko; (III) Provision of study materials \\ or patients: IS Brodetskyi; (IV) Collection and assembly of data: IS Brodetskyi, VE Dosenko; (V) Data analysis and interpretation: All authors; (VI) \\ Manuscript writing: All authors; (VII) Final approval of manuscript: All authors. \\ Correspondence to: Igor Sergeevich Brodetskyi. Room Number 12, St. Saksaganskogo 68, Kyiv, Ukraine. Email: i2g3o4@bigmir.net.
}

\begin{abstract}
Background The most common type of salivary gland tumor is pleomorphic adenoma. The genetic area of focus in the diagnosis of salivary gland tumors is a study of the role of miRNA.

Methods: Twenty-two patients with pleomorphic adenomas of the salivary glands were used for the examinations. The histological typing of the salivary gland tumors was performed when using routine staining with hematoxylin and eosin, as well as with immunohistochemistry. The expressions of miR-34a and miR-29a were evaluated by using reverse transcription and the quantitative polymerase chain reaction in a real-time setting. In addition, the study also calculated the levels of expression of miR-29a and miR-34a in the venous blood.
\end{abstract}

Results: The majority of patients-15 (68.18\%) and $22(100.00 \%)$ had a positive response to human papillomavirus (HPV) and pleomorphic adenoma gene 1 (PLAG1), respectively. The conducted analyses of the expressions of miR-34a and miR-29a showed that the highest expression was observed in the salivary gland tissue adjacent to the tumor $(1,052.02 \pm 367.20$ and $111.93 \pm 56.97$, versus $47.72 \pm 28.93$ and $8.12 \pm 4.40$ in the intact salivary gland tissue, respectively).

Conclusions: There was a sufficiently high level of miR-34a and miR-29a expressions in the tissues of the tumor of pleomorphic adenomas of the salivary glands when compared with the intact salivary gland tissue.

Keywords: MiR-29a expression; miR-34a expression; pleomorphic adenomas; salivary glands; correlation analysis; apoptosis

Submitted Feb 27, 2020. Accepted for publication Oct 20, 2020.

doi: 10.21037/gs-20-284

View this article at: http://dx.doi.org/10.21037/gs-20-284

\section{Introduction}

Most of the cases of salivary gland tumors are benign and only $20 \%$ are malignant (1). They occur in people over 60 years of age, with an equal distribution by gender (2). Salivary gland tumors show a high level of phenotypic, biological, and clinical heterogeneity. They occur in the major and minor salivary glands. Moreover, $80 \%$ of such cases occur in the parotid salivary glands, where $40 \%$ of the tumors are malignant (3). Pleomorphic adenoma (PA) is the most common type of salivary gland tumor, with $60-90 \%$ of salivary gland tumors being benign (4). PAs have a typical clinical picture that creates no difficulties for modern doctors in their diagnosis. Despite this, the misdiagnosing of this tumor remains high-up to $41.81 \%$ (5). The reason for this is that clinical and pathohistological diagnoses are different, and it is a normal situation for a tumor or a neoplasm. This creates a coincidence because in the early stages, they both have the same clinical signs and they look the same. The above-mentioned factors have encouraged scientists and doctors to employ advanced methods for tumor diagnosis-such as immunohistochemical and 
genetic diagnoses. The immunohistochemistry of tumors of the salivary glands, particularly PA, develops quite rapidly. At the present time, there are already enough known prognostic markers for a PA condition. For instance, etiologic-pleomorphic adenoma gene 1 (PLAG1), viralhuman papillomavirus (HPV), and Epstein-Bar virus $(\mathrm{EBV})$, as well as hormonal circumstances, such as estrogen, progesterone, and others (6).

The genetic area of focus in the diagnosis of salivary gland tumors is a study of the role of microRNAs (miRNAs). MiRNAs are small non-coding RNAs that consist of 21-23 nucleotides and they are found in all eukaryotic cells. Approximately 2,588 miRNAs are known today. In fact, in 2014, a single miRNA database was created, which now has 2,588 human miRNAs and 1,915 mice miRNAs. It has also been noted that miRNAs regulate about $60 \%$ of human genes (7). They regulate such biological processes as cell cycle control (8), apoptosis (9), metabolism (10), cell development, and differentiation (11). They are also involved in the development of various diseases, such as neurodegenerative (12) and metabolic disorders (13), and cancer (14). MiRNAs are responsible for the posttranscriptional expression of genes. Among miRNAs with different functions some of them have strongly pronounced proapoptotic (miR15a, miR-16-1, miR-29, miR-34a, miR34b, miR-34c, miR-1, and miR-214) and antiapoptotic (miR-17-5p, miR-20a, miR-21, miR-133, miR-146a, miR146b, miR-191, miR-14, miR-1d, miR-7, miR-148, miR204, miR-210, miR-216, miR-296, and miR-Lat) functions. Of particular interest are the pro-apoptotic miRNAs$34 \mathrm{a}$ and 29a. These two miRNAs are expressed in the majority of PAs of the salivary glands-at $96 \%$ and $84 \%$, respectively. Flores et al. 2017 indicated that in response to DNA damage, miR-34a as a p53 target, induced cell cycle arrest in G1, along with the apoptosis processes (15). Xiong et al. (16) suggested that in hepatocellular carcinoma, miR29a might promote apoptosis via a mitochondrial pathway involving the MCL1 and BCL2 proteins. From another point of view, Kinoshita et al. (17) proposed the role of miR29 a as a tumor suppressor for squamous cell carcinoma of the head and neck, due to its ability to suppress tumor cell invasion. There are no data about using of the level of these miRNAs as a marker of disease and a prediction marker in preoperative period.

However, there is only one work in which a tumor biopsy sample was used to determine the expressions of the miR$29 a$ and miR-34a genes, by comparing the expression levels of both of these molecules between adenocarcinomas and
PAs, with the absence of a control group (15). There are no articles in the literature that describe the expressions of miR-34a and miR-29a in other biopsy specimens, except for in the tumor itself, the salivary gland tissue that is adjacent to the tumor, the intact gland (control group), and the blood. These scenarios determined the purpose of the current research. The objective of the study was the determination of the expressions of miR-34a and miR-29a in the tissues of PAs of the large salivary glands, the salivary gland tissue adjacent to the tumor, the intact tissue of the salivary gland that was not associated with the tumor, and the venous blood. These data may answer the question about possibility to use analysis of mentioned miRNAs level as a predictive marker for disease diagnostic. This investigation will also help to answer the question about necessity of a surgical removal of the border zone.

We present the following article in accordance with the MDAR reporting checklist (available at http://dx.doi. org/10.21037/gs-20-284).

\section{Methods}

\section{Patients and sampling}

This study was approved by the Ethics Committee of the Bogomolets National Medical University approved the study on May 5, 2016 (protocol number 95). All the participants have signed informed consent that included the information about future publication of the data. The study conformed to the provisions of the Declaration of Helsinki (as revised in 2013). As materials for the examination of 22 patients with benign tumors of the major salivary glands [parotid salivary gland-20 (90.9\%) and submandibular salivary gland-2 (9.09\%)]—PAs were chosen. Among the patients, there were five men $(22.73 \%)$ and 17 women $(77.27 \%)$. The average age of the patients was $39.70 \pm 14.91$ years. All of the patients underwent general clinical examinations [laboratory, computed tomography (CT) or magnetic resonance imaging (MRI), ultrasonic diagnosis]. For the correlation analyses, the following clinical parameters were determined: age, disease duration, tumor size, and the distance from the skin's surface to the tumor. The last two indicators (tumor size, the distance from the skin's surface to the tumor) were determined according to computer tomography.

\section{Immunobistochemistry}

After the excision of the neoplasm, the pathohistological 
and immunohistochemical examinations were conducted. The histological typing of the salivary gland tumors was performed when using routine staining with hematoxylin and eosin, as well as with immunohistochemistry. The investigation was conducted based on the excisional biopsies of PAs of the salivary glands in 22 patients. For the research, $10 \times 10$ size-tumors of up to $4 \mathrm{~mm}$ in thickness were collected from the removed parotid and the submandibular salivary glands. The cut tumor pieces were inserted into cassettes and then placed into the cassette holder, which was moved to a fixation container with $10 \%$ formalin that was buffered with $\mathrm{pH} 7.4$ for 16 hours. The materials were condensed in paraffin when using a Histos 5 Histoprocessor (Milestone, Italy), according to the program for surgical materials at a 4-mm thickness. After completing the paraffin-condensing program, the cassettes were removed from the paraffin block of the histoprocessor and then moved to the filling station of a Hestion TEC-2800 Embedding Center, where they were filled with molten paraffin. This was followed by freezing in the refrigerator module of a Hestion TEC2800 Cryo Console. From the obtained paraffin blocks, histological sections were made 5-microns-size thick when using a Microm HM 325 microtome (Thermo Scientific, Germany). The sections were stained with hematoxylin and eosin for the histopathological examinations of the tumor, for the morphometry, and for the calculations of the volume of the viable tumor tissue.

The immunohistochemistry of Epstein-Barr virus and HPV was performed with monoclonal mouse anti-EpsteinBarr virus latent membrane protein 1 (LMP1) Clones CS. 1-4 (Dako IS 753, Denmark), and anti-HPV polyclonal rabbit antibody p16 (CDKN2A) (Thermo Scientific PAL. 16662), with the use of an EnVision ${ }^{\mathrm{TM}}$ FLEX detection system (Dako, Denmark), and PLAG1 monoclonal antibody (M02) clone 3B7 (China). The antigen masking was carried out in a citrate buffer of $\mathrm{pH} 6.0$ at $95^{\circ} \mathrm{C}$. The obtained histological tissue samples were studied and they were photographed using an Olympus CX41 Microscope with a QuickPHOTO MICRO 2.3 Camera and Software under standardized conditions. The tissue samples that had a definite positive reactivity were used for the positive control. For the negative control, a procedure without the use of primary antibodies was performed.

\section{$R N A$ isolation, reverse transcription and $q P C R$}

The total amount of RNA was isolated from the benign tumors of the salivary gland (PAs) tissues (the tumor itself, the tissue adjacent to the tumor of the salivary gland, the intact tissue of the salivary gland that was not associated with the tumor) and the venous blood when using the phenol-chloroform extraction method. The researchers then measured the RNA concentrations and their purity with a NanoDrop ${ }^{\mathrm{TM}}$ Spectrophotometer ND1000 (NanoDrop ${ }^{\mathrm{TM}}$ Technologies Inc., USA).

The miR-29a and miR-34a expressions were estimated by means of reverse transcription and the quantitative polymerase chain reaction ( $\mathrm{qPCR}$ ) in a real-time setting. Reverse transcription was performed by using a TaqMan MicroRNA Reverse Transcription Kit (Applied Biosystems ${ }^{\mathrm{TM}}$, USA), with a specific primer for the miRNAs, and $10 \mathrm{ng}$ of total RNA. For the real-time qPCR TaqMan MicroRNA Assays (Applied Biosystems ${ }^{\mathrm{TM}}$, USA), the following were used: U6 snRNA, ID 001973 (as the endogenous control), hsa-miR-29a (Assay ID002447), and hsa-miR-34a (Assay ID000426).

The temperature cycles were as follows: the first step of the initial denaturalization was $95^{\circ} \mathrm{C}$ for $10 \mathrm{~min}$, then 40 cycles at $95^{\circ} \mathrm{C}$ for $15 \mathrm{~s}$, and 50 cycles at $60{ }^{\circ} \mathrm{C}$ for $60 \mathrm{~s}$. The expression levels of the miRNAs were normalized up to U6 snRNA and then presented in relative units (RU). The amplification was performed by using a 7500 Fast RealTime PCR System (Applied Biosystems ${ }^{\mathrm{TM}}$, USA). The obtained results were analyzed with the help of the 7500 Fast Real-Time PCR software package (18). Up- or downregulation of the miRNAs expression level was considered as increase or decrease of the miRNA level revealed in tumor tissue comparing to the intact tissue.

\section{Statistical analysis}

The data analysis was performed using the $\mathrm{R}$ statistical environment (version 3.5). All of the quantitative factors were checked for normality of the data distribution when using the Kolmogorov-Smirnov test. Levene's test was used to check the equality of the dispersions between the groups. One-way analysis of variance (ANOVA) was used to determine the differences between the group averages for the variables that tracked the equality of variances between the groups, as well as with Welch's $t$-test and the Brown-Forsythe test when the variances significantly differed. Bonferroni a posteriori tests were used to correct the multiplicity of the tests. Correlation analyses using Pearson's correlation coefficient ( $r$ ) were used to estimate the relationship between the quantitative variables. The results were considered statistically significant at $\mathrm{P}<0.05$. 
Table 1 The main clinical indices of the patients with pleomorphic adenomas of the large salivary glands $(\mathrm{n}=22)$

\begin{tabular}{lc}
\hline Clinical indices & Results \\
\hline Age (years) & $39.70 \pm 14.91$ \\
Duration of the disease (months) & $66.08 \pm 30.58$ \\
Size of the tumor (cm) & $6.27 \pm 4.66$ \\
Distance from the surface of the skin to the tumor $(\mathrm{mm})$ & $5.60 \pm 2.74$ \\
\hline
\end{tabular}

Table 2 The main immunohistochemical indices of the viruses in the patients with pleomorphic adenomas of the large salivary glands ( $\mathrm{n}=22)$

\begin{tabular}{lcccc}
\hline $\begin{array}{l}\text { P16 HPV monovirus } \\
\text { positive reaction }\end{array}$ & $\begin{array}{c}\text { Monovirus EBV } \\
\text { positive reaction }\end{array}$ & $\begin{array}{c}\text { HPV + EBV } \\
\text { positive reaction }\end{array}$ & $\begin{array}{c}\text { HPV + EBV } \\
\text { negative reaction }\end{array}$ & PLAG1 \\
\hline $15(68.18 \%)$ & - & $3(13.64 \%)$ & $4(18.18 \%)$ & $22(100.00 \%)$ \\
\hline
\end{tabular}

HPV, human papillomavirus; EBV, Epstein-Bar virus; PLAG1, pleomorphic adenoma gene 1.

Table 3 The descriptive statistics of the levels of expression of miR-34a by groups (the tumor tissue adjacent to the tumor salivary gland, the intact salivary gland tissue that was not associated with the tumor) in the patients with pleomorphic adenomas of the large salivary glands

\begin{tabular}{lcccc}
\hline Groups of biological tissues & Amount $(\mathrm{n})$ & Mean & Std. deviation & Std. errors \\
\hline Intact (vital) gland & 16 & 47.72 & 115.73 & 614.66 \\
Tumor & 15 & 539.09 & 1,93 \\
Adjacent gland & 13 & $1,052.02$ & $1,323.98$ & 367.20 \\
\hline
\end{tabular}

\section{Results}

The main demographic and clinical indices of the patients with PAs of the large salivary glands $(n=22)$ that were included in the study are indicated in Table 1 . The average age of patients was $39.70 \pm 14.91$ years, duration of the disease $66.08 \pm 30.58$ month. Average size of the tumor was $6.27 \pm 4.66 \mathrm{~cm}$.

As Table 2 shows, the majority of patients-15 (68.18\%) and $22(100.00 \%)$ had a positive response to HPV and PLAG1, respectively (Figure 1A,B).

Levene's test was used to evaluate the dispersion equality at the expression levels of miR-34a and miR-29a between the groups. Since the variance between the groups was not equal $(\mathrm{P}<0.05)$, the difference between the mean values of the expression levels of miR-34a and miR-29a were analyzed when using Welch's $t$-test and the Brown-Forsythe test. As can be seen from the results with the use of oneway ANOVA, the study found a statistically significant difference in the levels of expression of miR-34a and miR29a. The descriptive statistics of the levels of expression of miR-34a by groups (the salivary gland tissue adjacent to the tumor, the intact salivary gland tissue that was not associated with the tumor) in the patients with PAs of the large salivary glands is demonstrated in Table 3. The descriptive statistics of the levels of expression of miR-29a by groups (the salivary gland tissue adjacent to the tumor, the intact salivary gland tissue that was not associated with the tumor) in the patients with PAs of the large salivary glands is shown in Table 4. In order to find out which groups differed among themselves, Bonferroni's correction was used. The results are shown in Table 5.

Thus, the researchers found that the expression levels of miR-34a and miR-29a statistically and significantly differed between the groups (the tumor-intact salivary gland tissue and the salivary gland tissue adjacent to the tumor-the intact salivary gland tissue) and (the salivary gland tissue adjacent to the tumor-the intact salivary gland tissue), respectively. The levels of expression of miR-34a are represented in Figure 1C. The levels of expression of miR29a are represented in Figure 1D.

In addition, the study also calculated the levels of expression of miR-29a and miR-34a in the venous blood (Table 6). 
Table 4 The descriptive statistics of the levels of expression of miR-29a by groups (the tumor tissue adjacent to the tumor salivary gland, the intact salivary gland tissue that was not associated with the tumor) in the patients with pleomorphic adenomas of the large salivary glands

\begin{tabular}{lcccc}
\hline Groups of biological tissues & Amount $(\mathrm{n})$ & Mean & Std. deviation & Std. errors \\
\hline Intact (vital) gland & 17 & 8.12 & 18.17 & 167.70 \\
Tumor & 20 & 80.58 & 205.43 & 37.49 \\
Adjacent gland & 13 & 111.93 & 56.97 \\
\hline
\end{tabular}

Table 5 Bonferroni's correction test for the groups of biological tissue from the patients with pleomorphic adenomas of the large salivary glands (with the expression of miR-29a)

\begin{tabular}{lcc}
\hline Comparison groups & The difference in the mean & Statistically significant \\
\hline Adjacent gland-intact salivary gland tissue & 103.81 & $\mathrm{P}<0.05$ \\
\hline
\end{tabular}
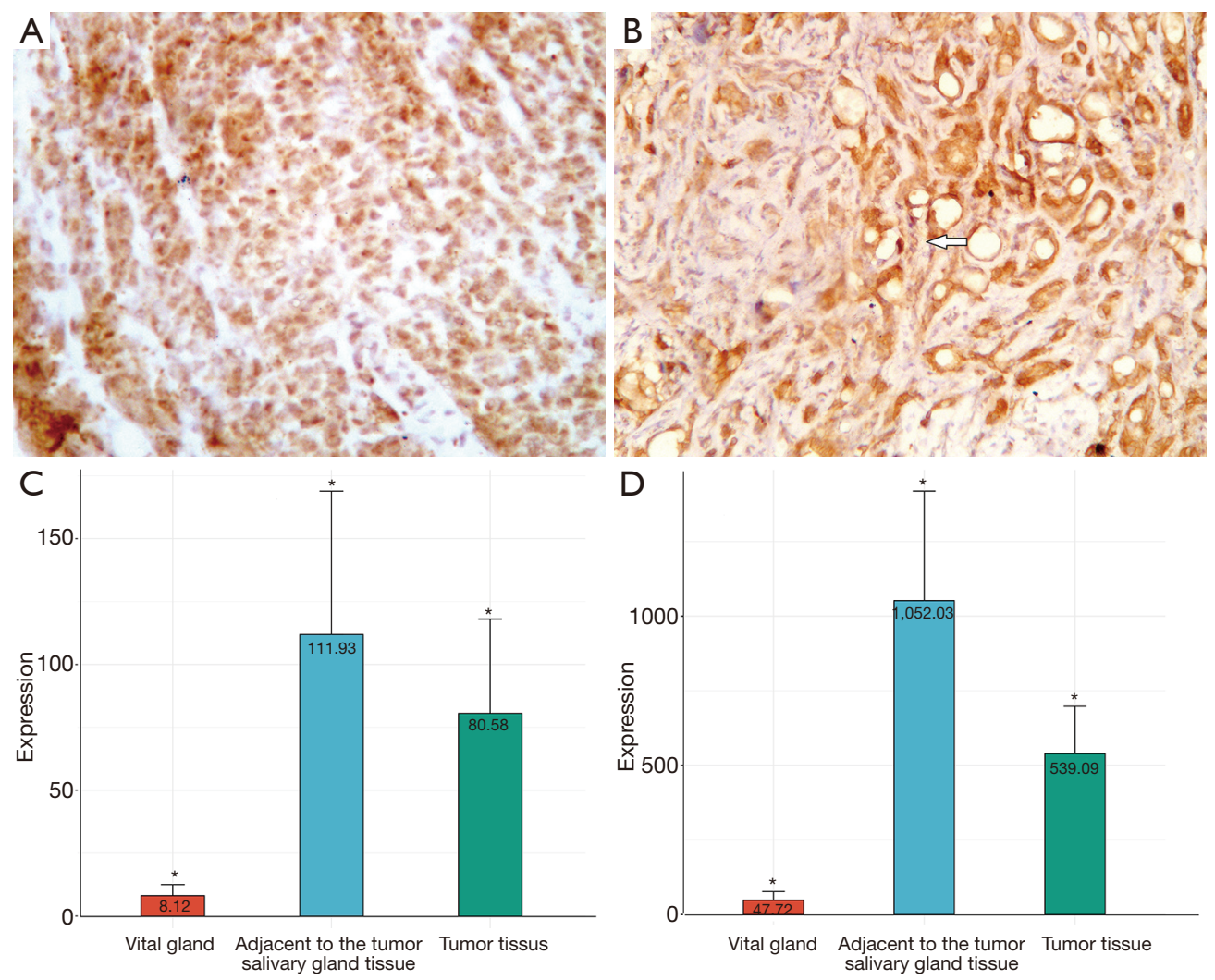


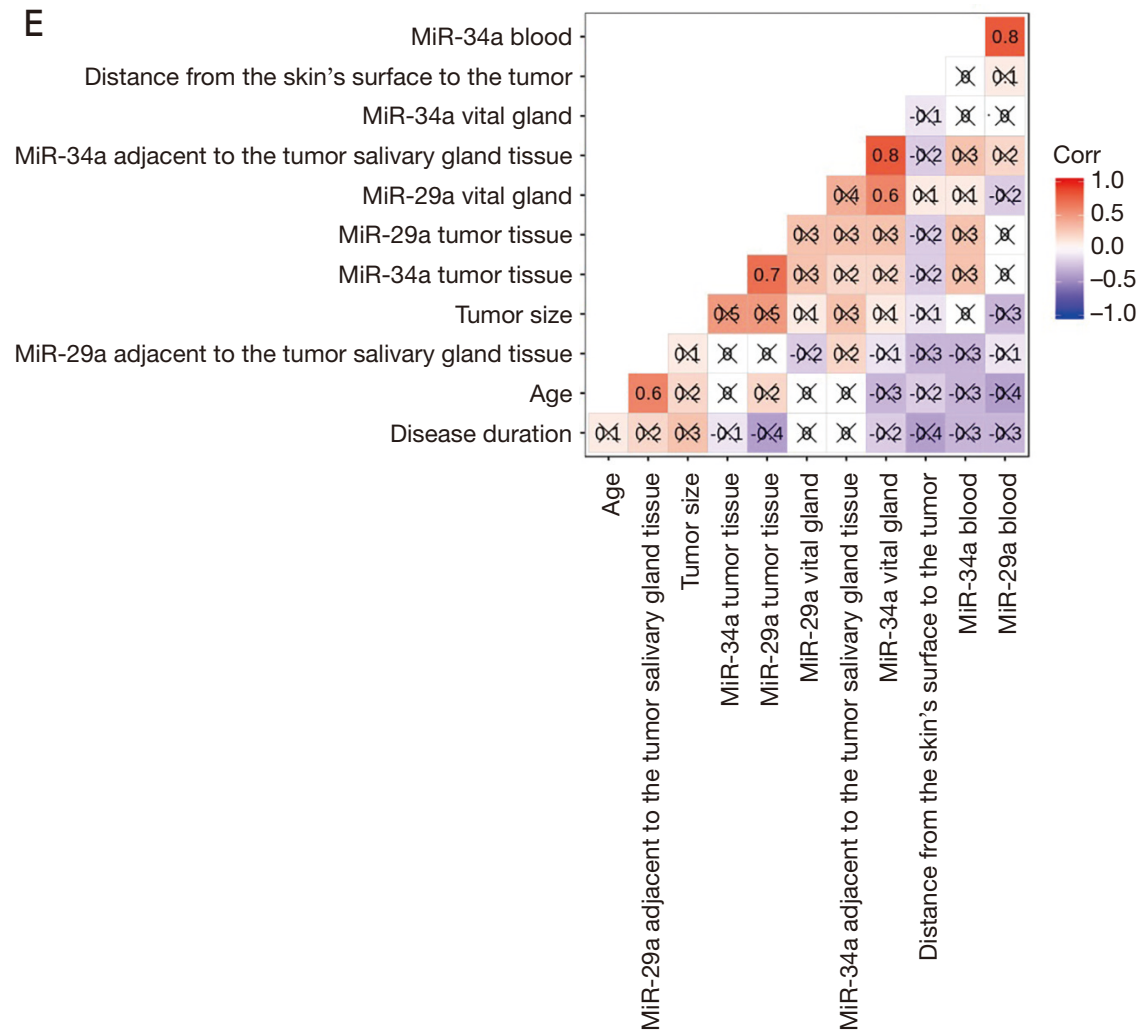

Figure 1 Photo of a histological tissue samples. (A) Pleomorphic adenoma of the parotid salivary gland of patient L., 33 years old. Magnification, $\times 200$. Positive nuclear-cytoplasmic immunohistochemical reaction to HPV type 16. (B) Photo of a histological tissue sample of pleomorphic adenoma of the parotid salivary gland of patient B., 68 years old. Magnification, $\times 200$. Strong positive $(+++)$ nuclearcytoplasmic immunohistochemical reaction to PLAG1 (indicated by an arrow). (C) The levels of expression of miR-34a in the patients with pleomorphic adenomas of the large salivary glands by groups (the tumor, the salivary gland tissue adjacent to the tumor, the intact salivary gland that was not associated with the tumor). *, statistically significant result. (D) The levels of expression of miR-29a in the patients with pleomorphic adenomas of the large salivary glands by groups (the tumor, the tissue adjacent to the tumor of the salivary gland tissue, the intact salivary gland that was not associated with the tumor). *, statistically significant result. (E) The correlation analyses of the expression indices of miR-34a, miR-29a, and the clinical parameters (age, disease duration, the tumor size, and the distance from the skin's surface to the tumor) in the patients with pleomorphic adenomas of the major salivary glands.

Table 6 Expressions of miR-29a and miR-34a in the venous blood

\begin{tabular}{lcccc}
\hline Groups of biological tissues & Amount (n) & Mean (r.u. miR/U6) & Std. deviation & Std. errors \\
\hline Blood with miR-34a & 16 & 17.45 & 23.73 & 6.12 \\
Blood with miR-29a & 13 & 4.31 & 4.60 & 1.32 \\
\hline
\end{tabular}

As can be seen from the data in Tables 3,4,6, the expression levels of miR-34a and miR-29a were lower than those in the intact group. Thus, the use of blood as a diagnostic marker for PA when using both of these miRNAs was impossible. The conducted analyses of the levels of expression of miR-34a and miRNA-29a revealed that among the 4 groups of indicators (the tumor itself, the salivary gland tissue adjacent to the tumor, the intact salivary gland that was not associated with the tumor, and the venous blood) in the patients with PAs of the large salivary gland, the highest expression was noted in the salivary gland tissue adjacent to the tumor group 
$(1,052.02 \pm 367.20$ and $111.93 \pm 56.97$, versus $47.72 \pm 28.93$ and $8.12 \pm 4.40$, respectively).

The correlation analyses were performed in order to evaluate the possible relationships between the miRNA expression levels. The results are shown in Figure $1 E$ and only statistically significant associations show.

Thus, the correlation analyses of the expression indices of miR-34a, miR-29a, and the clinical parameters (age, disease duration, the tumor size, and the distance from the skin's surface to tumor) in the patients with PAs of the major salivary glands determined the presence of 5 statistically significant associations of the correlated pairs [miR-29a tumor and miRNA-34a tumor-0.7 $(\mathrm{P}<0.05)$; miRNA-29a intact gland and miRNA-34a intact gland-0.6 $(\mathrm{P}<0.05)$; miRNA-34a salivary gland tissue adjacent to the tumor and miRNA-29a intact gland-0.8 $(\mathrm{P}<0.05)$; miRNA-34a blood and miRNA-29a blood-0.8 $(\mathrm{P}<0.05)$; and miRNA29 a salivary gland tissue adjacent to the tumor and age -0.6 $(\mathrm{P}<0.05)]$.

As can be seen from the obtained data, the expressions of both miRNAs in the tumors were interdependent; that is, by increasing the content of one miRNA, this caused an increase in the content of the other. When taking into account the proapoptotic functions of both of the miRNAs (29a and 34a), this may indicate the activation of apoptosis in the tumor process among the PAs of the major salivary glands.

The study also observed the same dynamics in the pairs of both miRNAs for the intact gland and the venous blood, which may indicate the activation of the major proapoptotic miRNA groups in response to the tumor process. The presence of a statistically significant correlation in the pairs of adjacent miRNA-34 and the intact miRNA-29 may indicate, on the one hand, the additional protective function of the organism, and the response to the tumor process in the gland tissue. However, an increase in the expressions of miRNA-34 in the adjacent tissue of the salivary gland led to increased processes of cell proliferation and differentiation. This included the appearance of tumor cells (the border zone with the tumor), which under certain conditions, may contribute to the proliferation of tumor cells in the tumor and in the salivary gland tissue adjacent to the tumor, stimulating the progression of tumor growth and increasing its size. Only one clinical indicator had a statistically significant correlation with the levels of expression of the miRNAs when considering the age of the patients. It was found that with an increase in the patients' age, the expression levels of miRNA-29 in the salivary gland tissue adjacent to the tumor increased. This indicated that the older person was - there were more formed protective antitumor mechanisms found in the border area next to the tumor.

\section{Discussion}

Genetic research is a promising survey method that is onwards and upwards in medicine. Among its advantages, one can single out, not only the ability to verify tumors of different localizations but to also develop advanced pharmacological treatments for tumors (19).

In the diagnosis of salivary gland tumors, a large number of miRNAs, from 22 to 95 , can be employed. This greatly expands the range of verification of salivary gland tumors and it enables the creation of different groups of drugs, affecting the different links of tumorigenesis (20). Among the majority of miRNAs, the molecules that are responsible for the control of apoptosis (proapoptotic) - miR15a, miR16-1, miR-29, miR-34a, miR-34b, miR-34c, miR-1, and miR-214-are of considerable interest for salivary gland tumors.

The conducted analyses of the levels of expression of miR-34a and miR-29a among the patients with PAs of the major salivary glands showed that the highest expression was observed in the salivary gland tissue adjacent to the tumor. This was almost 20 and 10 times greater than in the intact gland tissue, which did not border with the tumor $(1,052.02 \pm 367.20$ versus $47.72 \pm 28.93$ r.u., and $111.93 \pm 56.97$ versus $8.12 \pm 4.40$ r.u., respectively). The levels of expansion of miR-34a and miR-29a in the tumor tissues were 10 times higher than in the intact tissue $(539.09 \pm 158.70$ versus $47.72 \pm 28.93$ r.u., and $80.58 \pm 37.49$ versus $8.12 \pm 4.40$ r.u., respectively). Flores et al. (2017) showed expressions of miR-34a and miR-29a in the tumor tissues at levels of 8 and 6 (conventional units), respectively (15). The level of $\mathrm{miR}-34 \mathrm{a}$ is in 1.95 times greater $(1,052.02 \pm 367.20$ versus $539.09 \pm 158.70 ; \mathrm{P}<0.05)$ and $\mathrm{miR}-29 \mathrm{a}$ is in 1.37 times greater $(111.93 \pm 56.97$ versus $80.58 \pm 37.49 ; \mathrm{P}<0.05)$ in the tissue of the salivary gland adjacent to the tumor comparing to the tumor tissue. Such an increase in the expressions of miR-34a and miR-29a in the tissues of the gland adjacent to the tumor may be associated with the protective (restraining) function of the body, thus restricting the spread of tumor cells into the surrounding tissues of the salivary gland. The miR-34a and miR-29a molecules are proapoptotic, thus, increased apoptosis may be one of the limiting factors for the spread of the tumor. However, an increase in the 
proliferation and differentiation of the cells in the salivary gland tissue adjacent to the tumor may be considered as a manifestation of transformation into the tumor component.

This study has once again confirmed at a transcriptional level, the need not only for the excision of the tumor (partial parotidectomy) but also for the performance of a subtotal resection, with the removal of the salivary gland adjacent to the tumor, where proliferative changes can occur despite the barrier function of possibly increased apoptosis in this area. Immunohistochemical evaluation of etiological factors in this study support this recommendation. p16 is an inhibitor of cyclin-dependent kinases 4 and 6 which activate the negative cell cycle regulator protein pRB. $\mathrm{pRB}$ in turn downregulates p16 expression in a loop mechanism. HPVs can interfere with this regulatory circuit by its virtue to inactivate $\mathrm{pRB}$ and thus lead to the overexpression of p16. Thus, increase in p16 protein level is a non-direct marker of all types of HPVs infections. P16 considered as an HPV marker in many publications and was shown to be present in a lot of head and neck tumors. PLAG1 is a protooncogene whose overexpression is a crucial oncogenic event in salivary gland PAs. Our data indicates that the majority of patients-15 (68.18\%) and $22(100.00 \%)$ had a positive response to HPV marker p16 and PLAG1, respectively. These findings may explain that despite of high expression of proapoptotic miRNAs in the salivary gland tissue adjacent to the tumor, proliferation and possible malignization still occur in this area.

Such an indicator of biomaterial, as the blood, showed levels of expression of miR-34a and miR-29a lower than normal (intact gland) $(17.45 \pm 6.12$ versus $47.72 \pm 28.93$, and $4.31 \pm 1.32$ versus $8.12 \pm 4.40$, respectively). However, this was not statistically significant; therefore, it cannot be a diagnostic criterion for the genetic verification of PAs at the preoperative stage (PA salivary gland). In turn, a sufficiently high level of expressions of miR-34a and miR29a in the tissues of the PAs of the large salivary glands when compared to the norm (intact salivary gland tissue) $(539.09 \pm 158.70$ versus $47.72 \pm 28.93$, and $80.58 \pm 37.49$ versus $8.12 \pm 4.40$, respectively), can be used as a genetic marker for the verification (identification) of this type of tumor, together with marker PLAG1, which was expressed in 22 $(100.00 \%)$ of the cases.

High levels of expression of proapoptotic miR-34a and miR-29a in the tissue adjacent to the salivary gland tumor in patients with PAs of the major salivary gland when compared to normal (intact salivary gland tissue) $(1,052.02 \pm 367.20$ versus $47.72 \pm 28.93$, and $111.93 \pm 56.97$ versus $8.12 \pm 4.40$, respectively) indicated on tumor cell lesions in the salivary gland tissue adjacent to tumor. Therefore, this may be one of the causes of recurrence and the progression of tumor growth.

Despite the increase in the content (expression) of both proapoptotic miRNAs in the tumor and in the salivary gland tissue adjacent to the tumor, tumor development continued. Thus, the question arises, why do the antitumor mechanisms of humans, including apoptosis, not lead to tumor regression when the miRNA content in the tumor is 10 times higher than normal? A possible answer to this question is the presence of additional mechanisms of protection in the tumor itself, which is self-improving and adapting in the human body. As a rule, malignant tumors inhibit the process of apoptosis, reducing the expressions of most proapoptotic miRNAs, allowing them to grow rapidly and to progress the tumor, promoting the rapid invasion of the adjacent regions. It can be assumed that the high content of proapoptotic miRNAs in benign tumors (PApleomorphic adenoma of the salivary glands) indicates the active protective mechanisms of the body, by inhibiting the active growth of the tumor. Clinically, this is expressed as slow growth of the tumor over a long time, with a slow invasion of the adjacent regions of the intact gland.

One possible factor that influences the process of apoptosis is a viral infection. Thus, HPV type 16 expresses an E6 protein that binds to the ubiquitin ligase, with E6AP (a protein associated with E6), and p53, a key regulator of apoptosis (a tumor suppressor), and this influences its destruction. E6 can sequester p53 in the cytoplasm, meaning that it cannot perform its functions in an activation of the nuclear transcription (21). There are also findings that HPV E6 controls the expressions of the cellular miRNAs, such as miR-23b, miR-218, and miR-34a. The molecule miR-34a is controlled through p53, and the loss of this factor through the E6-mediated degradation leads to the inhibition of a wide range of cell cycles and apoptosisrelated gene expressions (22).

Thus, the conducting of a genetic study of PAs of the salivary glands when using miR-34a and miR-29a allows for identifying possible ways to influence these markers on the pathogenesis of PAs, and this confirms, at the genetic level, the need for a subtotal resection of the salivary gland.

\section{Conclusions}

(I) Whenever there was a sufficiently high level of miR$34 \mathrm{a}$ and miR-29a expressions in the tissues of the 
large salivary glands PAs compared with the intact salivary gland tissue evaluated as 10:1, these molecules can be used as a genetic marker for the verification (identification) of this type of tumor.

(II) When conducting correlation analyses of patients with PAs of the large salivary glands, with different fragments of biopsy material, the study found that the expression levels of miR-34a differed significantly between the groups (the salivary gland tissue adjacent to the tumor-the intact tissue of the salivary gland), and for miR-29a, there was an absence of a statistically significant group.

(III) This study of biopsy material from those patients with PAs of the large salivary glands at the genetic level (by the expressions of miR-34a and miRNA-29a) has again confirmed the need not only for the enucleation of the tumor (partial parotidectomy) but also for performing a subtotal resection, with the removal of the salivary gland adjacent to the tumor.

\section{Acknowledgments}

Funding: None.

\section{Footnote}

Reporting Checklist: The authors have completed the MDAR reporting checklist. Available at http://dx.doi.org/10.21037/ gs-20-284

Data Sharing Statement: Available at http://dx.doi. org/10.21037/gs-20-284

Peer Review File: Available at http://dx.doi.org/10.21037/gs20-284

Conflicts of Interest: All authors have completed the ICMJE uniform disclosure form (available at http://dx.doi. org/10.21037/gs-20-284). The authors have no conflicts of interest to declare.

Ethical Statement: The authors are accountable for all aspects of the work in ensuring that questions related to the accuracy or integrity of any part of the work are appropriately investigated and resolved. The study was conducted in accordance with the Declaration of Helsinki (as revised in 2013). The Ethics Committee of the Bogomolets National Medical University approved the study on May 5 ,
2016 (protocol number 95). The participants gave informed consents before taking part in this research.

Open Access Statement: This is an Open Access article distributed in accordance with the Creative Commons Attribution-NonCommercial-NoDerivs 4.0 International License (CC BY-NC-ND 4.0), which permits the noncommercial replication and distribution of the article with the strict proviso that no changes or edits are made and the original work is properly cited (including links to both the formal publication through the relevant DOI and the license). See: https://creativecommons.org/licenses/by-nc-nd/4.0/.

\section{References}

1. To VS, Chan JY, Tsang RK, et al. Review of salivary gland neoplasms. ISRN Otolaryngol 2012;2012:872982.

2. Licitra L, Grandi C, Prott FJ, et al. Major and minor salivary glands tumors. Crit Rev Oncol Hematol 2003;45:215-25.

3. Adelstein DJ, Koyfman SA, El-Naggar AK, et al. Biology and management of salivary gland cancers. Semin Radiat Oncol 2012;22:245-53.

4. Matjakin EG, Drobyshev AJu, Azizjan RI. Recidivy smeshannyh opuholej okoloushnyh sljunnyh zhelez [relapses of mixed salivary gland tumors]. Stomatologija 2010;89:75-7.

5. Brodetskyi IS, Malanchuk V. Analysis of archive material of patients with salivary gland neoplasms according to the department of O.O. Bogomolets National Medical University for the last five years. J Stoma 2019;72:70-6.

6. Malanchuk VO, Brodetskyi IS, Krotevich MS. Complex immunohistochemical evaluation of pleomorphic adenomas of the salivary glands. Healthy Aging Research 2019. doi: 10.35248/har.2019.8.09.

7. Bartel DP. MicroRNAs: target recognition and regulatory functions. Cell 2009;136:215-33.

8. Carleton M, Cleary MA, Linsley PS. MicroRNAs and cell cycle regulation. Cell Cycle 2007;6:2127-32.

9. Jovanovic M, Hengartner MO. miRNAs and apoptosis: RNAs to die for. Oncogene 2006;25:6176-87.

10. Boehm M, Slack FJ. MicroRNA control of lifespan and metabolism. Cell Cycle 2006;5:837-40.

11. Harfe BD. MicroRNAs in vertebrate development. Curr Opin Genet Dev 2005;15:410-5.

12. Jin P, Alisch RS, Warren ST. RNA and microRNAs in fragile X mental retardation. Nat Cell Biol 2004;6:1048-53.

13. Poy MN, Eliasson L, Krutzfeldt J, et al. A pancreatic islet- 
specific microRNA regulates insulin secretion. Nature 2004;432:226-30.

14. Lu J, Getz G, Miska EA, et al. MicroRNA expression profiles classify human cancers. Nature 2005;435:834-8.

15. Flores BC, Lourenço SV, Damascena AS, et al. Altered expression of apoptosis-regulating miRNAs in salivary gland tumors suggests their involvement in salivary gland tumorigenesis. Virchows Arch 2017;470:291-9.

16. Xiong Y, Fang JH, Yun JP, et al. Effects of microRNA-29 on apoptosis, tumorigenicity, and prognosis of hepatocellular carcinoma. Hepatology 2010;51:836-45.

17. Kinoshita T, Nohata N, Hanazawa T, et al. Tumoursuppressive microRNA-29s inhibit cancer cell migration and invasion by targeting laminin-integrin signalling in head and neck squamous cell carcinoma. Br J Cancer 2013;109:2636-45.

18. Mytsyk Y, Dosenko V, Borys Y, et al. MicroRNA-15a

Cite this article as: Brodetskyi IS, Malanchuk VO, Dosenko VE. Expressions of microRNA-29a and microRNA-34a in pleomorphic adenomas of salivary glands. Gland Surg 2020;9(6):1914-1923. doi: 10.21037/gs-20-284 expression measured in urine samples as a potential biomarker of renal cell carcinoma. Int Urol Nephrol 2018;50:851-9.

19. Acunzo M, Romano G, Wernicke D, et al. MicroRNA and cancer--a brief overview. Adv Biol Regul 2015;57:1-9. Erratum in: Adv Biol Regul. 2015 May;58:53.

20. Denaro M, Navari E, Ugolini C, et al. A microRNA signature for the differential diagnosis of salivary gland tumors. PLoS One 2019;14:e0210968.

21. Graham SV. The human papillomavirus replication cycle, and its links to cancer progression: a comprehensive review. Clin Sci (Lond) 2017;131:2201-21.

22. Wang X, Wang HK, McCoy JP, et al. Oncogenic HPV infection interrupts the expression of tumorsuppressive miR-34a through viral oncoprotein E6. RNA 2009; 15:637-47. 